\title{
A CASA COMO INSTRUMENTO PARA O BEM-ESTAR DO USUÁRIO
}

\section{ARTIGO ORIGINAL}

DIETZ, Karine Maria ${ }^{1}$

DIETZ, Karine Maria. A casa como instrumento para o bem-estar do usuário. Revista Científica Multidisciplinar Núcleo do Conhecimento. Ano 06, Ed. 06, Vol. 01, pp. 66-80. Junho de 2021. ISSN: 2448-0959, Link de acesso: https://www.nucleodoconhecimento.com.br/arquitetura/bem-estar-do-usuario, DOI: 10.32749/nucleodoconhecimento.com.br/arquitetura/bem-estar-do-usuario

\section{RESUMO}

'Sentir-se em casa' é um sentimento natural e genuíno ao retornar à casa, ou pelo menos deveria ser. Para tanto, elementos como cor, textura, luz e forma, quando adequadamente escolhidos, transmitem conforto e bem-estar, tão necessários à nossa recuperação e sobrevivência diária. $\mathrm{O}$ artigo responde a seguinte problemática: o que faz a casa ser instrumento para o bem-estar do usuário? E para isso apresentar a importância do profissional de arquitetura e design de interiores na criação de um ambiente residencial que proporcione esse sentimento aos moradores. A definição do problema do artigo se deu após observação da necessidade de existência de um espaço para se recuperar a energia despendida ao longo do dia, sendo - normalmente - o local de retorno, a casa. Para o desenvolvimento dessa pesquisa foi realizada uma revisão bibliográfica acerca da importância do arquiteto na criação de um ambiente residencial que proporcione bem-estar aos usuários. Os resultados encontrados indicam que uma casa bem planejada, decorada, organizada e aconchegante transmite aos que ali residem, bem-estar, conforto, segurança e aconchego.

Palavras-chave: Ambiente, Arquitetura de Interiores, Bem-estar, Design, Usuário.

\footnotetext{
${ }^{1}$ Graduação em Arquitetura e Urbanismo pela Universidade Católica Dom Bosco (2017) e Pós-graduação em Design de Interiores: Ambientação e Produção do espaço pelo IPOG (2020).
} 


\section{INTRODUÇÃO}

Esse artigo insere-se na área de Psicologia Ambiental - subárea da Psicologia - e surgiu da necessidade de entender o que torna a casa um instrumento de bem-estar físico e mental do usuário e como o arquiteto pode facilitar esse processo. Para responder a esse questionamento, optou-se por realizar uma Revisão Bibliográfica narrativa.

A inter-relação pessoa-ambiente, numa perspectiva de mútua influência, é o objeto de estudo da Psicologia Ambiental. Entende-se que, tanto as pessoas modificam os ambientes, como os ambientes têm poder sobre o comportamento das pessoas. Segundo Moser (2005), uma área que se propõe estudar a inter-relação pessoaambiente deve focar sua investigação tanto dos usuários do ambiente como do ambiente em si. Estudos acerca do ambiente são necessariamente interdisciplinares, abrangendo áreas do conhecimento voltadas para a compreensão do ambiente natural (Zoologia, Biologia, Geologia e estudos florestais) e construído (Ergonomia, Arquitetura, planejamento da paisagem e planejamento urbano). De modo mais específico, esse artigo encaixa-se em um ramo ainda mais recente da Psicologia Ambiental, a Psicologia do Design de Interiores, que tem por fundamento essencial, o amplo universo de investigação neurocientífica das emoções humanas, e visa contribuir para que os lares sejam espaços promotores de bem-estar e qualidade de vida.

A Psicologia aplicada ao design de interiores é hoje uma disciplina rica, que se baseia em muitos outros estudos para desvendar a complexidade da interação do homem com o meio: Psicologia, teoria da cultura, Filosofia, estudos do gênero, História e Antropologia, bem como a história do Design, Arquitetura, artes e artesanato, mobiliário e moda. (COSTA, 2015). Talvez, por isto, para que alguém sentir-se feliz em casa, não é preciso ter uma situação financeira privilegiada, mas é necessário respeitar as características e particularidades de cada morador. (SCARDUA, 2009). Seja como for, identificar os fatores que promovem bem-estar, sentimentos e emoções positivas, sensações agradáveis e satisfação com o lar tem sido a meta dos psicólogos envolvidos na formulação de uma arquitetura da felicidade, de modo que o foco da 
casa passa a ser o indivíduo e não apenas conceitos abstratos de estética ou funcionalidade. (SCARDUA, 2009). Conhecer o indivíduo, sua história, suas experiências e vivência de mundo é de extrema importância, pois é através delas que é construída sua identidade residencial e sua forma de perceber e avaliar sua residência atual.

Esse estudo torna-se importante para confirmar a ideia de que o arquiteto não é apenas um prestador de serviço de decoração, mas importantes parceiros na busca pelo bem-estar físico e mental do usuário. Ocorre que, muitas vezes, por falta de informação e receio deste profissional deixar o espaço com a "cara" deste e não a do real usuário, muitas pessoas optam por não o contratar, perdendo a oportunidade de ter um espaço único, planejado especialmente para elas. E para Alain Botton, este é um medo genuíno. Em seu livro A arquitetura da Felicidade (2007), ele defende que ao construir uma casa ou decorar um cômodo, as pessoas querem mostrar quem são, lembrar de si próprias e ter sempre em mente como elas poderiam idealmente ser. $\mathrm{O}$ lar, portanto, não é um refúgio apenas físico, mas também psicológico, pois é ele o guardião da real identidade de seus habitantes.

\section{REFERENCIAL TEÓRICO}

O referencial teórico abordou alguns estudos sobre o conceito de casa, sobre a interrelação pessoa-ambiente, numa perspectiva de mútua influência, e sobre itens e elementos importantes a serem considerados no projeto residencial.

\subsection{CASA É REFÚGIO}

O conceito de casa é mais conhecido como sendo uma construção destinada à habitação humana, apresentada como um espaço que deve estar adequado ao modo de vida de seus moradores e às características climáticas da paisagem onde está inserido. A casa se relaciona intimamente com o homem, pois sua configuração depende da situação e do modo de vida de quem a habita e quando este lhe infunde sua rotina, a transforma em algo próprio e pessoal, assumindo uma dimensão simbólica. 
No espaço privado da casa, ao contrário do que ocorre no público, podemos ser nós mesmos. É no espaço doméstico que não nos intimidamos para mostrar tanto nossos aspectos desagradáveis quanto os agradáveis. A casa, portanto, é um refúgio no qual nos permitimos nos expressar integralmente. (SCARDUA, 2011).

A noção de refúgio nos remete a história da nossa espécie. Para nossos ancestrais, a caverna, a primeira casa, era o espaço onde estavam protegidos das ameaças externas, onde era possível relaxar e cuidar uns dos outros sem temer o ataque de um predador ou da fúria da natureza. Inicialmente escondido em grutas naturais, 0 homem foi pouco a pouco personalizando sua habitação, acumulando tesouros e projetando suas fantasias na decoração das paredes (GRUBITS, 2003). Para Costa (2015), ao construir uma casa ou decorar um cômodo, as pessoas querem mostrar quem elas são e nessa perspectiva, a casa, além de refúgio físico, torna-se também refúgio psicológico, onde é guardada a identidade de quem a habita. A casa representa o ser humano em seus elementos mais fundamentais, em sua essência.

[...] é graças à casa que um grande número de nossas lembranças estão guardadas e se a casa se complica um pouco, se tem porão e sótão, cantos e corredores, nossas lembranças têm refúgios cada vez mais bem caracterizados. Voltamos a eles durante toda a vida em nossos devaneios. (BACHELARD, 2008, p.24 apud CORDEIRO, 2015, p.68).

Gary Evans (2005), da Universidade Cornell, em Nova York, identifica que o bemestar numa moradia depende, em grande parte, da possibilidade de os moradores fazerem modificações na casa. Para Evans, poder decidir quanto à organização da casa cria um elo emocional entre morador e espaço. Não à toa, pesquisas sobre satisfação com a moradia apontam para o fato de que os proprietários costumam ser mais satisfeitos com seus lares do que os inquilinos.

Quando um espaço doméstico nos oferece a sensação de proteção, conforto e reconhecimento, ele contribui para o bem-estar físico e emocional, e sentir-se seguro num espaço reconhecido como próprio ajuda no combate ao estresse diário e na recuperação do desgaste do dia-a-dia, tão exigido nos espaços públicos, onde precisamos nos adequar. 
Homem e ambiente convivem num processo de interdependência, criando uma ligação íntima entre os processos psicológicos de percepção do espaço e os processos de criação desse espaço. Ainda, a maneira pela qual o homem modifica o ambiente é hoje um tema de muita relevância, pois os espaços são expressões culturais do homem ao mesmo tempo em que são suportes espaciais para a construção de sua identidade. Assim, é de extrema importância que o arquiteto ou o profissional que atua no ambiente compreenda como os materiais que participam desse ambiente têm influência na percepção do conforto. (ZALESKI, 2006, p. 19).

\subsection{PROJETO É BEM-ESTAR}

Desenvolver um projeto arquitetônico é criar "uma proposta de solução para um problema específico de organização do entorno humano, através de uma determinada forma construível, bem como a descrição desta forma e as prescrições para sua execução" (SILVA, 1998, p.39, apud SIQUIERA E FILHO, 2015, p.38-39). Para isso, são necessárias, dentre outras, quatro fases principais: o Estudo Preliminar, que diz respeito à coleta de dados e dfiniçaõ do Programa de Necessidades; o Anteprojeto, referente à proposta gráfica inicial da solução geral encontrada; o Projeto Executivo que, após aprovação da proposta e possíveis alterações anteriores, registra a solução definitiva, com a especificação da técnica construtiva, materiais e revestimentos escolhidos, bem como o detalhamentos julgados necessários; e o Acompanhamento da execução da obra - esta última não necessariamente realizada pelo autor do projeto. Todo o espaço deve ser pensado e planejado a partir de escolhas específicas para a sua utilização, considerando variáveis objetivas - como localização, ventilação, insolação, ruídos externos, dimensões e circulações mínimas necessárias - e subjetivas - cores, iluminação, elementos de decoração, dentre outros.

Falar de projeto arquitetônico é pensar o ambiente e suas diversas possibilidades, dentro das necessidades de quem vai usufruir do espaço. Para Rocha e Rocha (2015), o bom projeto é aquele que tem a propriedade de transmitir aos ocupantes a sensação confortante de "sentir-se em casa", traduzindo suas necessidades e desejos. É importante, também, considerar a necessidade de se aprofundar nossos conhecimentos sobre o homem como usuário, no sentido de compreender quem é 
aquele que, de fato, fará uso do espaço construído, e analisar os sentimentos que surgem na medida em que as características do projeto do ambiente são alteradas.

O profundo conhecimento das reais e específicas necessidades de um potencial grupo de usuários de um espaço habitável, as sim como seus hábitos e relações sociais normalmente estabele cidas dentro do ambiente doméstico, será de inestimável valor para que, ao se elaborar o projeto, atinjase o objetivo proposto: conferir ao usuário o domínio sobre o u so do produto adquirido - sua moradia - para que esse lhe seja de fato prazeroso, seguro e responsável por uma verdadeira melhora na qualidade de suas vidas - ou seja, o conforto doméstico, que embora muitas vezes apresenta do como tal, jamais deveria ser confundido com mercadoria. (CAMARGO, 2000, p. 05)

Os espaços são percebidos pelos indivíduos através de suas experiências, expectativas, preferências e referências. Os aspectos ligados à percepção do indivíduo definem o modo como ele se relacionará com ambiente, porém, nem sempre são levados em consideração na elaboração do projeto, ou por não seres reconhecidas, identificadas, ou mesmo por serem consideradas irrelevantes. Entretanto, quando o indivíduo interage com o ambiente, ele o experimenta a partir de suas emoções, análises e julgamentos. Rheingantz (2004) considera que a influência do ambiente construído no comportamento das pessoas é fundamental para a compreensão das inter-relações entre homem e ambiente.

Para Rocha e Rocha (2015), "a concepção de um novo espaço, principalmente os residenciais, deve levar em conta a personalidade de seus ocupantes, sua cultura, seu estilo de vida". Nesta etapa, deve-se estar atento a tudo o que diz o cliente, buscando conhecer a rotina e a intimidade dos usuários. Não é uma tarefa fácil, pois nem sempre as pessoas estão dispostas a falar de si a um estranho. $O$ arquiteto deve transmitir em seus projetos as necessidades que seu cliente demonstra, e para isso, passa a ter uma integração direta com sua vida pessoal, conhecendo suas histórias e raízes, criando um laço na criação do projeto. Assim, para ser adequado e funcional, um projeto deve estar o mais próximo possível de traduzir as necessidades e desejos atuais de seus usuários. 


\subsection{CONFORTO É BEM-ESTAR}

A arquitetura não pode ser encarada como um modificador do comportamento humano, a ponto de transformar a personalidade de indivíduos, mas ela pode influenciar na compreensão dos espaços e com isto proporcionar a satisfação ao usuário. Segundo Silva e Santos (2012, p.139), o conforto está sempre presente quando pensamos em qualificar um espaço, como se ele fosse expressão máxima da adequação entre desenho e uso, resultando em uma satisfação pessoal plena.

A palavra conforto está envolta em uma áurea de subjetividade. $\mathrm{O}$ significado desta palavra no idioma português está relacionado à sensação de bem-estar, que é difícil de definir objetivamente, pois varia em cada meio cultural e para cada indivíduo. No entanto, seus sinônimos comodidade e alívio dão pistas de que há algo relacionado ao aconchego no primeiro, e da ausência de desconforto no segundo. A relação entre conforto e alívio está ligada ao caráter mais físico, enquanto a relação entre conforto e comodidade, ao caráter mais subjetivo. (SILVA e SANTOS, 2012, p.139-140)

Para a Arquitetura de Interiores é de fundamental importância que o morador encontre conforto e bem-estar, e acima de tudo, sinta que aquele ambiente se transformou em seu lar. Alguns fatores relacionados ao conforto térmico, acústico, infraestrutura e ambiência, por exemplo, são decisivos na escolha do ambiente, contudo não são únicos. Existem fatores subjetivos que também influenciam nessas escolhas, normalmente relacionados à iluminação, cor e temperatura do ambiente e que interferem no humor dos usuários. Logo, o projeto de interiores - nesse artigo, residencial - permite que o ambiente seja desenvolvido para ser uma ponte de conforto e bem-estar às pessoas.

O 'bem-estar' é uma necessidade humana e o conforto uma condição para alcançá-lo. (RYBCZYNSKI, 1986). Sabendo que o conforto depende dos estímulos que o indivíduo recebe do ambiente, e de seus instintos, experiências e juízos, a postura do usuário, suas necessidades e modificações determinam requisitos mínimos de conforto. (ZALESKI, 2006, p.19-20).

$\mathrm{Na}$ relação pessoa-ambiente, o modo como o usuário compreende e entende esse espaço fazem parte de um sistema de aprendizagem adquirido com sugestões e associação de estímulos específicos. Aprender está condicionado às experiências do 
usuário, que por sua vez, influenciarão comportamentos futuros. Assim, compreender e entender o espaço permite identificar e selecionar estímulos que respondam às suas necessidades ou desejos.

\subsubsection{CONFORTO LUMINOSO}

Os objetos são percebidos pelo homem através da luz, e esta é também responsável pelo desencadeamento de ações biológicas e psicológicas no homem. Os ambientes devem ser planejados aproveitando ao máximo a iluminação natural, não só por motivos sustentáveis de economia de energia, mas também porque as pessoas apresentam um desempenho melhor com a luz natural. Segundo Fonseca (2000, apud Horevicz e Cunto, 2007 p.20):

A luz influencia o controle endócrino, o relógio biológico, o desenvolvimento sexual, a regulação de estresse e a supressão da melatonina, além de proporcionar um dinamismo no ambiente pelas tonalidades diferentes no decorrer do dia.

Deixar a luz natural entrar na casa não serve apenas para aquecer os ambientes e realçar as cores, mas é fundamental para ajudar o organismo a regularizar os ciclos cotidianos dependentes de hormônios e isto, coincidentemente, melhora o humor.

A percepção é um processo complexo pelo qual as pessoas selecionam, organizam e interpretam estes estímulos sensoriais em um esquema de coerência significante. Desta forma, o significado dado aos estímulos recebidos através da luz não está somente sujeito à fisiologia humana, em seu caráter objetivo, mas relaciona-se também à experiência, à atuação humana no meio, envolvendo todo o caráter subjetivo que o indivíduo carrega em suas relações com o mundo a sua volta. (VARGAS, 2009, p.04).

O modo como a luz é percebida nos permite fazer avaliações sobre o espaço físico e a qualidade dos ambientes construídos, além de poder pode provocar alterações de humor e comportamento. A luz que o olho humano recebe possibilita a observação e identificação de cores, formas, volumes e espaços, distinguidos pela eficiência visual e sensibilidade de cada indivíduo. 
Quando carregado de significados positivos, o indivíduo sente-se convidado a permanecer no local ou a frequentá-lo mais vezes; caso contrário, o ambiente será evitado. Tanto em um caso como em outro, as sensações visuais provocadas podem ser duradouras e podem influenciar atitudes futuras.

Em relação ao conforto luminoso, existem alguns critérios relativos à percepção visual - ângulos de visão e ofuscamento, contrastes e níveis de iluminamento - que influenciam relações com o lugar, positiva ou negativamente, podendo, nesse último caso, também provocar problemas de saúde. Assim, as sensações visuais agem no indivíduo provocando um processo que agrega significados e fatores subjetivos e objetivos, que por sua vez, implicam em questões fisiológicas e nos aspectos sócio culturais.

\subsubsection{CONFORTO ACÚSTICO}

A velocidade do desenvolvimento urbano trouxe novos desafios para a Arquitetura e no que diz respeito às questões acústicas. Ruídos externos como trânsito, alarmes, máquinas e equipamentos industriais, vizinhos barulhentos, música alta, ou mesmo uma conversa na sala do lado, podem ser grandes incômodos quando entram no nosso espaço. $O$ barulho atrapalha na concentração, interfere na qualidade do sono e pode desencadear quadros ainda mais graves, como perda da audição, zumbidos, ansiedade e nervosismo.

As escolhas de elementos e materiais a serem utilizados na casa - de construção, revestimentos e de decoração - podem influenciar diretamente no conforto acústico dos moradores. Além das questões de saúde, outro item de extrema importância e que muitas vezes passa desapercebido em relação ao Conforto Acústico é a privacidade. E quando falamos de "casa", o sentir-se em casa nos abre a certas permissões impensadas fora dela.

Todo tipo de parede, bem como esquadrias, têm um grau de isolamento acústico e, nesse sentido, é importante avaliar o nível de ruído ambiental antes de definir o layout ou escolher os materiais e revestimentos. Uma boa avaliação inicial contribui para a 
eficiência no desempenho do projeto final, sendo que, por vezes apenas uma modificação na distribuição do mobiliário já é suficiente para proteger os dormitórios do ruído de ruas e avenidas, outras vezes é necessário utilizar de materiais mais pesados e sistemas mais complexos para chegar ao mesmo resultado.

O avanço das tecnologias estruturais deixou as lajes mais delgadas e, com isso, as construções mais suscetíveis à transmissão sonora. As mudanças em nossos costumes quanto à escolha de acabamentos, por exemplo, também tiveram grande impacto nesta questão, quando substituímos o carpete pelo piso frio ou laminado, por exemplo, favorecemos a transmissão de ruídos de impacto entre pavimentos.

Para evitar este incomodo e atender as exigências das normas de desempenho, muitas vezes é necessária a utilização de novas tecnologias, como a execução de pisos "flutuantes", isolantes acústicos em forros e paredes (como lã de rocha e vidro), ou mesmo o uso de esquadrias acústicas, com vidros mais espessos ou duplos, capazes de reduzir mais de $90 \%$ dos ruídos externos.

Como solução mais rápida e sem sujeira para os problemas de ruídos, a utilização de tapetes e cortinas, painéis, e móveis estofados, como sofás e cabeceiras, são grandes aliados. Os tapetes, além de complementarem a decoração e aquecer os ambientes, ajudam a abafar os sons. As cortinas, por sua vez, dificultam a transmissão sonora de um local para outro, ainda mais quando são feitas com tecidos mais grossos. Essas características auxiliam na obtenção dos resultados de tratamento acústico, e por isso devem ser incorporados aos projetos de interiores.

\subsubsection{CONFORTO TÉRMICO}

O conforto térmico está relacionado às reações do organismo humano quando submetido a ambientes quentes e frios. Ambas as situações, em extremo, causam desconforto e, portanto, devem ser evitadas ao máximo pelo profissional no planejamento de um espaço. Cores e aberturas mal utilizadas, por exemplo, têm correlação direta com esses efeitos. Para que um ambiente apresente uma temperatura adequada, o ideal é esse requisito ser levado em conta desde o início do 
projeto, ou seja, desde a implantação do edifício no terreno, quando devem - em princípio - ser consideradas características como chuvas, umidade, ventilação, sombreamento e exposição solar, e vegetação, a fim de bem pensar a fachada do mesmo, posição e dimensionamento das aberturas, escolha de materiais e revestimentos adequada.

Entretanto, infelizmente essa não é realidade da maior parte dos edifícios e, por isso, muitas vezes o espaço interno da edificação acaba por não apresentar as melhores condições térmicas para aqueles que dele usufruirão. Para isso, o arquiteto deve utilizar artifícios e ferramentas que possibilitem o conforto térmico.

A substituição das esquadrias comuns por esquadrias com vidro duplo, persianas embutidas ou mesmo com brises-solei já podem, em determinados casos, melhorar as condições térmicas do ambiente. Pode haver também, a necessidade de criar outra parede, em dry-wall, com isolamento em lã de vidro ou rocha, a fim de conter o calor em uma fachada com grande exposição ao sol, por exemplo. Há situações em que apenas o uso de uma cortina black-out ou persianas já é suficiente para reter o calor.

O uso de aquecedores, ventiladores, aparelhos de ar condicionado ou exaustores é bastante comum, principalmente em casos de a edificação não ser pensada para que haja uma ventilação cruzada ou mesmo insolação adequada.

Conforto térmico, além de sensação física, é uma questão de percepção. Assim, tanto quanto no caso do conforto acústico, o uso de materiais e revestimentos adequados, além de móveis e itens de decoração, podem interferir, sendo de suma importância considerar o maior número de variáveis possível, tanto do espaço como do usuário, para chegar a um projeto interessante àquele que utilizará do ambiente usará.

\subsection{A COR COMO FERRAMENTA DE IDENTIFICAÇÃO}

A arquitetura e a psicologia são estudadas separadamente, entretanto, a inter-relação entre ambiente construído e comportamento humano é de grande importância, influenciando o modo de vida das pessoas de maneiras diversas. 
Cada lugar tem sua atmosfera específica, determinada por sua luz, cores e texturas, aromas, linhas e volumes arquitetônicos. E é essa atmosfera que torna cada lugar único, que os torna tão distintos, e é ela também a responsável pela comunicação da arquitetura com o ser humano, da casa com o morador.

No que diz respeito à cor, se observarmos ao nosso redor, ela está presente em tudo - fauna, flora e luz solar - e sua presença pode ser percebida por toda a história da humanidade. A cor influência direta e indiretamente o nosso cotidiano, e quando utilizada de maneira adequada, torna-se uma ferramenta importante no equilíbrio de ambientes e seres, gerando bem-estar, preservando à saúde, facilitando à comunicação entre as pessoas.

Apesar de a preferência por determinadas cores parecer algo relativo, existe um peso psicológico sobre isso, pois cada pessoa capta os estímulos externos conforme a estrutura dos seus sentidos. Ela possui uma força surpreendente, sem que necessite juntar elementos instrutivos ou sentimentais. A cor identifica espaços, pessoas e objetos. O processo de definição, de escolha das cores, é uma ciência que impõe equilíbrio e harmonia que vai muito além das questões estéticas, e a cromoterapia é exemplo disso, pois revela a influência que as cores têm na vida das pessoas.

\subsection{AMBIÊNCIA COMO FERRAMENTA DE APROPRIAÇÃO}

Segundo Malard (2017):

Habitar é cuidar, diz Heidegger (1971), portanto é um processo sem fim de construir, arranjar, arrumar, modificar, cuidar e embelezar os lugares. Nesse processo o homem se apropria dos espaços humanizando-os, modificando-os para dotá-los de sua própria natureza. Humanizar espaços significa torná-los adequados ao uso dos humanos; torná-los apropriados e apropriáveis. (p. 04)

Apropriação envolve uma total reciprocidade entre o usuário e o espaço, onde o usuário molda o lugar de acordo com suas necessidades e desejos, e este, em contrapartida, torna-se receptivo. Essa reciprocidade é a razão pela qual pessoas e grupos se identificam, ou não, com os diversos lugares que frequentam e vivem. 
Nessa perspectiva, a ambiência do ambiente é o que possibilita que haja harmonia entre pessoa-espaço.

A ambiência engloba uma série de aspectos objetivos e subjetivos, ambos com consequências comportamentais. Os aspectos objetivos referem-se às sensações corpóreas experimentadas num lugar, ativadas pelas condições térmicas, acústicas, luminosas e dimensionais; enquanto os aspectos subjetivos estão relacionados às sensações causadas pela forma como materiais, cores, texturas e formas são dispostos e combinados no ambiente.

Para Trevizan (2004, p. 01) “o usuário quando se apropria de 'seu lugar', busca através de um conjunto de símbolos e signos, marcar este território imprimindo nele uma identidade própria". Nesse sentido, é possível compreender a relação íntima existente entre morador e moradia, como se a casa fosse um espelho do seu eu, nos levando a perceber que a escolha de revestimentos, móveis e peças decorativas conta muito sobre a personalidade dos moradores de uma casa.

O ambiente simples, compreendido como aquele pensado a partir do que é essencialmente necessário e agradável aos sentidos de quem o habita, cria condições para que o foco da nossa atenção se volte a nós mesmos. Sem excessos desnecessários, nossa mente consegue interpretar adequadamente as informações do ambiente, fica mais fácil prestar atenção nos nossos sentimentos, pensamentos, sensações e emoções.

Cada objeto - mobiliário ou item de decoração - carrega uma significação nem sempre óbvia. A felicidade perene é alcançada por aqueles que conseguem decodificar a realidade, somente possível quando entendemos como as coisas ao nosso redor são afetadas, porque tudo tem importância, onde até o que parece uma simples peça na decoração, tem significado próprio e uma função simbólica sensível à forma como as pessoas recebem, ao que os seus olhares comunicam. 


\section{MÉTODOS}

A metodologia utilizada na realização desse artigo trabalhou com abordagem qualitativa, que, através de uma pesquisa bibliográfica, fundamentada em revisão literária acerca da importância do projeto de ambiente residencial e de algumas variáveis que devem ser consideradas em seu processo, proporcionarão bem-estar aos usuários.

\section{CONSIDERAÇÕES FINAIS}

Com base no material apresentado, compreendemos compreender o papel que 0 arquiteto no bem-estar das pessoas. Ao planejar o espaço, definir cores, texturas, materiais, iluminação, mobiliário e decoração, o profissional está personalizando o lugar, deixando-o particularmente único, dando ferramentas para que o morador se identifique com o ambiente, sinta confiança, segurança, estabilidade, e consequentemente, bem-estar.

O bem-estar é um fator psicológico que está vinculado às relações entre pessoa e ambiente e, nesse sentido, a ambientação é primordial para que quem vá usufruir do ambiente, sinta-se integrado e tenha sensações agradáveis quanto ao local. Nesta perspectiva, concluímos que - considerando as preferências e gostos do morador todo ambiente precisa ser planejado pensando no todo para que o principal objetivo seja seu conforto e bem-estar.

\section{REFERÊNCIAS BIBLIOGRÁFICAS}

BOTTON, Alain de. Arquitetura da felicidade. 1a edição. Rio de Janeiro: Rocco, 2007. 271 páginas. Título original: The architecture of happiness. Tradução de Talita M. Rodrigues.

CAMARGO, Erica Negreiros de. 0 apartamento feito para você. São Paulo: PÓS/ FAUUSP, $\quad$ n. 9, p. 170-175. 2000. Pagina 05. Disponível em: < 
http://www.revistas.usp.br/posfau/article/view/137382/133079 > Acesso em: 08/08/2020.

CORDEIRO, Nilson da Rocha. A casa em verso e prosa: canções, poesia e subjetividade do conceito de casa. Recife: UFPE/MDU, 2015. Disponível em: < https://repositorio.ufpe.br/bitstream/123456789/18010/1/A\%20CASA\%20EM\%20VE RSO\%20E\%20PROSA\%20\%5BDisserta\%C3\%A7\%C3\%A3o-MDU\%5D\%20\%20Nilson\%20da\%20Rocha\%20Cordeiro.pdf > Acesso em: 13/08/2020

EVANS, Gary. A importância do ambiente físico. Psicologia USP, v. 16, n. 1-2, p. 47-52, 1 jan. 2005. Disponível em: < https://www.scielo.br/pdf/pusp/v16n1-2/24643.pdf > Acesso em: 21/08/ 2020.

GRUBITS, Sônia. A casa: cultura e sociedade na expressão do desenho infantil. Psicol. estud., Maringá, v. 8, n. spe, p. 97-105, 2003. Disponível em: < https://www.scielo.br/pdf/pe/v8nspe/v8nesa12.pdf >. Acesso em: 21/08/2020.

HOREVICZ, Elisabete Cardoso Simão; DE CUNTO, Ivanoé. A humanização em interiores de ambientes hospitalares. Revista Terra \& Cultura: Cadernos de Ensino e Pesquisa, v. 23, n. 45, p. 17-23, set. 2018. ISSN 2596-2809. Disponível em: < http://periodicos.unifil.br/index.php/Revistateste/article/view/397 >. Acesso em: 21/08/2020.

MALARD, Maria Lucia. Os objetos do quotidiano e a ambiência. Escola de Arquitetura da UFMG. 2017. Disponível em: < https://www.researchgate.net/profile/Maria_Malard/publication/237229185_OS_OBJ ETOS_DO_QUOTIDIANO_E_A_AMBIENCIA/links/59ef4474aca2721ca5e9316e/OSOBJETOS-DO-QUOTIDIANO-E-A-AMBIENCIA.pdf >. Acesso em: 08/08/2020.

MOSER, Gabriel. Psicologia Ambiental e estudos pessoas-ambiente: que tipo de colaboração multidisciplinar?. Psicol. USP, São Paulo, v. 16, n. 1-2, p. 131-140, 2005. Disponível em < http://www.scielo.br/scielo.php?script=sci_arttext\&pid=S010365642005000100015\&lng=en\&nrm=iso $>$. Acesso em: 20/07/2020. 
RHEINGANTZ, Paulo Afonso. De corpo presente: sobre o papel do observador e a circularidade de suas interações com o ambiente construído. In: Seminário Internacional NUTAU, 2004, São Paulo. Anais, São Paulo: 2004. Disponível em: < http://www.prolugar.fau.ufrj.br/wp-

content/uploads/2017/10/corpo_presente_nutau2004_par.pdf > Acesso em: 08/18/2020.

ROCHA, Fabio; ROCHA, Sílvia. A casa nossa: quando a arquitetura e a psicologia se relacionam. Disponível em: < http://www.forumdaconstrucao.com.br/conteudo.php?a=42\&Cod=1313 >. Acesso em: 21/08/2020.

SILVA, Helga Santos da; SANTOS, Mauro César de Oliveira. O significado do conforto no ambiente residencial. UFRJ/ PROARQ, n 18, 2012. Disponível em: < https://cadernos.proarq.fau.ufrj.br/public/docs/Proarq18_OSignificadoConforto_Silva Santos.pdf > Acesso em: 20/07/2020.

SCARDUA, Angelita. Psicologia do design de interiores: em busca de uma arquitetura da felicidade. Disponível em: < https://angelitascardua.wordpress.com/2009/05/22/psicologia-do-design-deinteriores-em-busca-de-uma-arquitetura-da-felicidade/ > Acesso em: 31/07/2020.

SCARDUA, Angelita. A casa e seu significado para o bem estar físico e emocional. Disponível em: < https://angelitascardua.wordpress.com/2011/08/02/acasa-e-seu-significado-para-o-bem-estar-fisico-e-emocional/ > Acesso em 31/07/2020.

TREVIZAN, Nara. A decoração interna da casa, segundo os traços de caráter. In: Anais $1^{\text {a }}$ Convenção Brasil Latino América e 9ํㅡㄹ Congresso Brasileiro de Psicoterapias Corporais. Foz do Iguaçu/PR. Centro Reichiano, 2004. p. 01. Disponível em: < https://www.centroreichiano.com.br/artigos/Anais-2004/TREVIZAN-Nara-Adecoracao.pdf > Acesso em: 21/08/ 2020. 
VARGAS, Cláudia Rioja de Aragão. Os impactos da iluminação: visão, cognição e comportamento. 2015. Página 04. Disponível em: < http://www.jornaldainstalacao.com.br/img/artigos/Lumiere_161.pdf > Acesso em: $31 / 07 / 2020$.

ZALESKI, Caroline Bollmann. Materiais e conforto: Um estudo sobre a preferência por alguns materiais de acabamento e sua relação com o conforto percebido em interiores residenciais da classe média de Curitiba. Curitiba, PR: 2006. p. 19-20.

Enviado: Setembro, 2020.

Aprovado: Junho, 2021. 